PRIFYSGOL

Journal Article

\title{
Social care legislation as an act of integration
}

Davies, N., Livingston,W., Owen, E. and Huxley, P.

This article is published by Emerald Group. The definitive version of this article is available at:

https://www.emeraldinsight.com/doi/abs/10.1108/JICA-03-2016-0009

Recommended citation:

Davies, N., Livingston,W., Owen, E. and Huxley, P. (2016), 'Social care legislation as an act of integration', Journal of Integrated Care, Vol.24, No.3, pp.139-149. doi: 10.1108/JICA-03-2016-0009 
Title

'Social Care Legislation as Acts of Integration'

\section{Article classification}

Research paper

\section{Abstract \\ Purpose}

This paper investigates Health and Social Care integration, through a specific exploration in North Wales within a short window of time between the assent of the Social Services and Well-being (Wales) Act 2014 and its implementation in 2016.

\section{Approach}

The findings are based on the experiences of Health and Social Care professionals from six Local Authorities and one regional Health Board working in a management role with strategic responsibility, gathered from an online survey $(n=43)$, semi-structured face-to-face interviews $(n=14)$, and supplemented with reflective interviews with regional coordinators responsible for facilitating cross-organisational working $(n=2)$.

\section{Findings}

Senior managers are devoting considerable energy to understanding the implications of the new legislation, ensuring that their organisations will be ready and able to successfully implement it. This work is perceived to be commensurate with wider agendas to transform and integrate working practices and services, influenced by a range of financial, environmental, organisational, social and policy factors.

Value

This research has direct implications for stakeholders in North Wales, having already been used to shape conversations about integration in the region, and furthermore builds upon existing knowledge in the academic and professional field of integration, with additional limited wider implications for policy and research.

\section{Keywords}

Care Act, integration, legislation, organisational change, social services, transformation 


\section{Introduction}

Health and Social Care integration is perceived to be a politically and morally desirable goal (Bull et al 2016, Glendinning, 2003), and has been pursued in various guises in previous legislation, including the Children's Act 1989, Community Care and NHS Act 1990, and Health Act 1999 (Alcock 2008); and in current legislation, as in the Care Act 2014 and Social Services and Well-being (Wales) Act 2014.

There are multiple examples of this policy-driven integration in practice, including Joint Care Planning Teams, Primary Care Trusts, Health and Well-being Boards, and Joint Financing (Jones, 2011) - illustrating various models of integration, from informal coordination and partnership working, to full structural integration, and generating a considerable body of evidence on how to implement integration. Factors known to facilitate integration include positive working relationships between local leaders (Gleave, 2010), embedding a shared vision and shared language from the start (Gleave, 2010; Timms and Ham, 2013), ensuring that the vision for integration prioritises patient outcomes (Lunts, 2012), and involving a wide range of stakeholders, not just the 'usual suspects' (Fisher and Thomson, 2006). Understood to a lesser extent, is what happens post-implementation - how effective integration is over time (Lunts, 2012; Stewart and Macintyre, 2013), particularly from the perspective of patients, service users and carers (Caine, 2014; Heenan and Birrell, 2009).

There are a broad range of definitions of integration in academic and policy discourse, which makes it difficult to compare outcomes between models with materially different interpretations of integration (Petch et al., 2013; Robertson, 2011). The absence of a shared definition of integration can also translate into a practical barrier to communication between stakeholders, especially, argues Petch, in the context of Health and Social Care where "there is a real danger that people are talking about the same arrangement using different terms or, conversely, using the same term to refer to different configurations" (2011).

The Social Services and Well-being (Wales) Act 2014 ('the Act') promotes a person-centred view of integration - calling for the "co-operation and partnership by public authorities with a view to improving the well-being of people" (National Assembly for Wales, 2014) echoing the rhetoric and spirit of preceding Welsh government policies Fulfilled Lives, Supportive Communities (2007) and Sustainable Social Services for Wales (2011). The Act was the first piece of legislation embarked upon by the Welsh Government following the devolution of additional law-making powers (post-Government of Wales Act 2006 and 2011 referendum), and had a significant remit, to replace the swathe of UK Social Care legislation dating back to 1948, including the aforementioned integration focused acts, with a single legislative framework. This can be understood as a response to a Law Commission review, recommending that the existing legal framework, a "confusing patchwork of conflicting statutes", be replaced with a single Act, to clarify provisions for care and support (Law Commission, 2011).

This paper offers an exploration of integration, based on the experiences of senior managers working in Health and Social Care in North Wales. The findings presented are from a broader 
study of individual professional and organisational preparedness for the Social Services and Well-being (Wales) Act 2014 (Livingston et al., 2015).

\section{Methods}

The research was designed and directly commissioned by the North Wales collaboration partnership who wanted to understand the existing evidence base for integrated and multiagency working, and the strengths and weaknesses of the current North Wales approach; as well as be guided towards considerations (but not recommendations) for the future. The work was initiated, monitored and reviewed by a Project Advisory Group, composed of representatives from four organisations and the research team. The study involved a comprehensive literature review, online survey $(n=43)$, semi-structured interviews $(n=14)$, and reflective interviews $(n=2)$.

\section{Literature review}

The purpose of the literature review was to provide the collaboration partnership with examples that helped to contextualise the Act, illustrate successful integration, and understand the likely implications of Integrated Health and Social Care in Wales. It was also used to inform the development of the survey and interview schedule.

\section{Survey}

The online survey used open and closed questions to explore preparedness for the Act, and processes of transformation including integration. A link to the survey was promoted to a purposive sample, defined as professionals working in a management role with strategic responsibility with one of six Local Authorities or the regional Health Board. A total of 73 people participated in the online survey. One Local Authority did not participate in the survey, and another Local Authority responded in very high numbers, raising questions about eligibility criteria being met. Out of the 73 total responses, 43 were retained for full analysis, and $\mathbf{3 0}$ were excluded, analysed separately and published in an appendix of the full report (Livingston et al., 2015). Respondents were distributed across three tiers of management: middle management $(n=18)$, senior management $(n=15)$, and executive level $(n=10)$. The majority of respondents were from Local Authorities $(n=36)$, with comparatively few based in Health $(n=7)$.

\section{Interviews}

The survey was the primary method of recruitment for interviews, inviting respondents to leave their contact details if they wished to participate in a follow-up interview. The invitation to participate was also extended to senior managers in the single Local Authority that did not engage with the survey.

The target was to interview 15-20 professionals across the seven organisations and three levels of management. A total of 14 people participated in an interview, with at least one interview from each organisation. The views of Local Authority staff $(n=13)$ were represented in greater numbers than the views of Health staff $(n=1)$. The interviews followed a structured 
schedule, exploring change, integration and perceived priorities. Towards the end of the research, additional reflective interviews were conducted with two regional collaboration officers (individuals who may be in a unique position to consider comparative and collective organisational preparedness), in order to gauge the extent to which the findings mirrored or contrasted their own experiences and perceptions. This presented an opportunity for the emerging themes to be verified or challenged, while also eliciting fresh findings about the regional changes taking place or yet to take place.

All interviews were compared with a set of pre-defined codes informed by the literature review and survey analysis, and analysed against new codes that emerged from the interview process.

The potential limitations of the study are discussed further on.

\section{Findings}

Unsurprisingly, the Act is perceived to be a significant piece of legislation, and has been a key preoccupation for the organisations engaged in this research in North Wales. It is considered to represent a significant extension of existing directions for Health and Social Care, which will have consequences for organisations in terms of culture, outcomes, processes and structure, and the way that they work with each other. Proactive preparation consistent with the Act appears to have begun before the legislation was introduced, enabled by awareness of wider policy trends, and compelled by a range of financial, environmental, organisational, policy and social factors. Though across the board change has been welcomed, numerous challenges to implementing integrated working have been identified - some 'typical' of Health and Social Care integration, for example, a lack of resources, organisational and political instability competing priorities or demands on time, and a lack of a clear shared vision for integration (Robertson 2011); and others specific to North Wales, notably the perceived over-emphasis in the Act on the responsibilities being met by Social Services, and the delay in the release of detailed guidance about the Act from central government.

\section{A new direction for North Wales}

The Act is the symbol of localised developments in a new direction for Health and Social Care in North Wales. (Dooris 2013) The overarching aspiration is to transform and integrate working practices and services, which is likely to involve changes to practice, processes and roles and responsibilities - including a focus on outcomes, improving population well-being, early intervention, prevention, recovery, more signposting, co-production, and broader statutory and third sector involvement.

The Act itself has not been the driving force for integration; it has been motivated by a combination of financial, environmental, social, organisational and policy pressures. The Act was described as legitimising and complementing the prevailing "direction of travel".

"The mantra now is one sector, one workforce, but I think we've been working to that beforehand". 
Participants offered a broad range of interpretations of what integration is, and what it can deliver (Shaw et al 2011). Integration was described by one participant as an opportunity for "doing things differently, together", and was evoked by others through discussions about greater colocation, joint working, shared responsibility, shared resources, and services being designed around user need. Typically very high expectations of integration were expressed: remove duplication, align services, enable organisations to share risk, save money, and offer better outcomes for people accessing the (and implicitly equal high expectations of the new direction for North Wales).

A key factor driving integration was communicated as the need to reduce dependency on services, in response to increased pressures on organisations and communities from austerity measures, poverty levels, and a shortage of appropriate, affordable housing.

"The idea is you know we achieve their outcomes, build their resilience to cope with things themselves so that they don't come back to us, not that they repeatedly come back to Social Services you know, we want to be seeing reductions in re-referrals, shorter times with Social Services, things like that".

Typical of such organisational pressures (Robertson 2013) current levels of dependency on services were perceived to be unsustainable, and perceived to be going against the grain of emerging philosophies about cultivating resilience, independence and wellbeing in communities.

\section{Acquaintance with change}

Many participants were working for their current sector (or an aligned sector) during the introduction of the Children Act 1989, and drew comparisons between this and the new Welsh Act; firstly the similarity of philosophy, of trying to move away from protection, toward prevention and client involvement; and secondly, the parallel expectations of revolutionary transformation.

A level of recent organisational restructuring, causing much change, instability and uncertainty was perceived to have taken some focus away from learning about, and responding to the Act. Yet, further re-organisation was felt to be needed, as existing organisational structures and boundaries have not been wholly conducive to working in an integrated way. Participants identified the impending Local Authority restructuring in Wales (published its Draft Local Government (Wales) Bill in November 2015, after the completion of this research), as possibly mitigating some of the current difficulties. The Bill proposes radical structural and procedural changes for a 2020 implementation, and as such will continue to cast a shadow over on-going implementation activity.

Preparation for the Act has been facilitated by complementary changes made prior to the development of the Act. In one Local Authority, this included the "re-structure of Social Services Departments to create Community Well Being Service". Some changes of emphasis within current service provision (commensurate with the Act) have also taken place across the region, such as the establishment of enablement services, and development of integrated safeguarding policies and processes. Though there was little evidence about 
work between Social Care and Health involving higher levels of integration - at the level of shared services, resources and vision.

\section{Sharing knowledge and responsibility}

The Act itself promotes a person-centred (i.e. citizen-, patient-, client-, service user-centred) view of integration. Although this was acknowledged by many participants, the primary focus of discussions of integration were on the implications for key statutory organisations

Awareness about the Act (and the changes the Act implies) were perceived to be very low among the general public. Participants suggested that members of the public who are aware of recent or imminent changes to their own care, may not be aware of why the changes were happening. Equally, members of the public whose services had not yet been affected may have expectations based on historic relationships with Health and Social Care, expectations which cannot be met going forward. There was concern that changes or cuts to services could eventually be attributed to (and 'blamed on') on Social Services, as the named organisation in the title of the Act.

"I can see why a lot of people outside might perceive that [...] they're just doing this to save money."

There was also thought to be a lack of awareness among organisations outside of Local Authorities and the regional Health Board, and it was unclear where responsibility for raising awareness and sharing information was perceived to lie.

"WHEN the implications of the legislative change and the practice guidance is finalised and issued our priority will be educating our staff over the implications for their practice, language, terminology etc. Main challenge will be the awareness amongst partner agencies of their role and responsibilities"

Implementation of the Act thus far in North Wales, appears to have been predominantly top-down, delivered from the Welsh Government to the leaders and managers of key organisations; who then have been responsible for feeding this down to operational staff and other stakeholders. Within some organisations, workforce development programmes have been used to involve staff and raise awareness, for example through briefings, training and workshops. While overall, participants seemed confident that they understood the implications of the Act (36 out of 43 respondents to the survey agreed or strongly agreed with that statement), when asked to elaborate in the survey and the interviews, many felt they had not received the detail. Participants across all organisations said they were awaiting further guidance from the Welsh Government before making certain decisions or plans. However, the extent to which they felt that the lack of clarity and guidance impacted on their organisational preparedness for the Act, differed across organisations. Some participants expressed confidence to make decisions in the absence of guidance, where others did not, and were awaiting guidance before acting - which could indicate some differences between organisations in the level of understanding (or interpretation) of the Act, or the perceived level of autonomy and local discretion to make changes. Furthermore, it 
could suggest that organisations are reverting to (or have not moved away from) independent decision-making, over collective, cross-organisational decision-making.

Participants said that the Act as it was, left question marks over roles and responsibilities, and what service users and carers could expect from new services. In the survey, when asked about the extent to which they thought the Act had clarified what service users and carers could expect from Health, Social Care and other statutory bodies, there was little collective agreement. Roughly half of respondents said that they agreed or strongly agreed (17) that it had, and the other half disagreed or strongly disagreed (19). In terms of roles and responsibilities, a greater number of survey respondents felt that the Act had been clear about Social Care (34), compared with service users and carers (22), non-statutory services (19), Health (18) and other statutory bodies (14).

The spirit of the Act was perceived to compel and promote integrated working, with the purpose of building collective responsibility for population health and wellbeing. The wording of the Act itself, however, was perceived to imply that Social Care should be expected to take the largest share of responsibility.

"I think the biggest weakness of all is calling it the Social Services and Well-being Act".

The nomenclature of the Act was a point of frustration for Social Care participants. The reference to Social Services in the title (and the omission of Health) was perceived to imply a primary responsibility contradicting the perceived spirit of shared responsibility through integration.

\section{What do the regional coordinators think?}

Two regional coordinators, with responsibility for facilitating work across boundaries, suggested that a lot of energy had already gone into developing service user-led outcome measures - including regional collaboration on piloting new National Outcomes Framework, and Social Services Improvement Agency (SSIA) Aggregating Personal Measurements. Interestingly this did not figure in the wider interviews. Work yet to be done includes consideration of how these outcomes measures can be aggregated into performance indicators and regional needs assessments.

This research identified the lack of a shared definition of integration, which according to the regional coordinators had already been acknowledged by the regional Integrated Services Board. A regional definition was evidently outlined in a 2014 Statement of Intent. That this also didn't make it into any other interviews or survey responses, suggests that this policy has not trickled down into practice or a working understanding of integration.

\section{Discussion}

The findings of the research do far more to consolidate existing knowledge than provide new ways of understanding - the potential for the research to achieve the latter being somewhat constrained by the timing of the research itself. Organisations are still in the early stages of change, and the shape of integration is unlikely to be fully realised until sometime 
after the 2016 implementation. Policy implementation is often better understood in reflection, than during those moments of implementation.

The Welsh Government aspirations for the Act; meeting needs, emphasising prevention promoting independence, increasing user voice and developing sustainable provision (Welsh Government 2016) are visible in previously heralded legislative changes for example Children's Act 1989, 2004, Health Act 1999 (Alcock 2008). Further the repeated need to assert such, and in the case of the Act, to have a specific section related to integration (Part 9) entitled 'Co-operation and Partnership' suggests that the aspirations of previous legislation have yet to be met. What is perhaps newer in the current legislation is; a) the fusing of children and adult services, b) the more directive approach to mandate an increasing multiplicity of community orientated partnership provision, what Alcock (2008) refers to as the 'double devolution' to communities and citizens and c) a reduction in the standardisation of process based assessment and delivery.

Given such national government focus, it is not surprising that the development of an integrated approach to Health and Social Care provision has been a key priority in North Wales, with the Act sharpening thinking and conversations about integration. The perceived shortcomings of the Act (notably nomenclature and the delay of guidance) have highlighted the need for greater clarity of roles and responsibilities, both between and beyond the regional Health Board and Local Authority Social Care departments, and to firmly establish what patients, service users and carers can and should expect from Health and Social Care services under the new Act.

To date, knowledge about (and responsibility for) the Act has been concentrated within a small group of stakeholders (including politicians, civil servants, and statutory Social Care and Health) with comparatively little shared elsewhere. Even at the time of writing, the flurry of training activity on the eve of the Act remains concentrated on Local Authority Social Services staff. A significant task yet to be managed is the shared development of a coherent vision for integration and the "consistent communication of [this] vision to a wide range of stakeholders" (Petch, 2013).

It has been argued that integration is most effective when patient outcomes are placed at the centre of the vision (Cameron, 2007; Caine, 2014; Petch, 2013). The Act infers a personcentred view of integration, calling for the "co-operation and partnership by public authorities with a view to improving the well-being of people" (National Assembly for Wales, 2014, emphasis added). Although participants engaged with this aim to improve population wellbeing, they also listed a wide range of other financial, environmental, social, and policy factors motivating the turn towards integration. In North Wales, the large number of factors driving integration gives individuals and organisations confidence that they are "heading in the right direction', and is perceived to be providing organisations with some momentum on this journey. However, it does raise some questions about the extent to which services can be person-centred when there are so many other desired outcomes from integration. The lack of public awareness (at the time of the research) about and engagement with the Act and engagement with the Act makes these questions all the more pertinent and should be a key consideration for the region going forward. 
Integration has primarily been discussed as a matter of organisations working together across their existing professional boundaries. An alternative approach based on a philosophy of inclusive practice, is to create new professional boundaries around the Act and integration, promoting the distribution of power, status and influence, as well as free lines of communication amongst stakeholders (Dooris, 2013, Humphries 2011). This may be more successful given the known disparity of status between Health and Social Care, and between the statutory sector and the voluntary sector (Bull et al 2016, Cameron et al., 2009); and in North Wales the perceived disproportionate burden of responsibility for the implementation of the Act on Social Care.

\section{Research limitations / implications}

\section{Limitations}

This research was funded through a one-off annual allocation from central government, which (as is typical) placed time and size restrictions on the research. These restrictions were further compounded by recruitment and data collection challenges. Through the Project Advisory Group, it was agreed that recruitment would be more successful if survey invitations were sent via email addresses within the constituent organisations, rather than a 'cold calling' approach from a university email address. It is unclear whether or not this decision increased participation. However, given that (a) communication with one local authority was ambiguous and appeared to induce over-recruitment, and b) it cannot be assumed that communication even took place in the non-responding authority, this must remain a point of contention.

A considerable proportion of the total number of responses received were from a single organisation in a single tier of management (middle management). This number was higher than the average number of responses from other organisations in this tier of management (33 vs. two). It was also higher than the number of individuals likely to hold a position of middle management and have strategic responsibility, within a single organisation. This suggested that the majority of responses in this cohort would not meet the criteria for participation. Three (of the 33) respondents completed optional fields about their job role and could be validated as middle management with strategic responsibility. As there was no way of validating the role of the remaining 30 , the researchers could not include their responses with confidence in the main body of the full report.

Despite the possible limitations of researchers not controlling the appeal to participate, the project appealed to senior managers for their time during a period of immense challenges, and competing demands and priorities. It is thus likely to have not been a priority for many. In a sense this is in part reflected in the sense that the data provides of a sense of waiting for rather than acting in implementation of something not yet in statutory force. This possible perception of a priority not yet owned may also explain the very low level of health participation. The name of the Act inviting a focus on social services. This situation is likely to be compounded by such a regional organisation as seeing its contribution on an agency level rather than proportionate to number of staff. Not untypical in such multi-agency 
perspectives is to see one representative from each local authority and only one representative from regional organisations like health, probation and police, despite their greater size or remit.

This research was designed to focus on the perspectives of 'traditional' Health and Social Care stakeholders (i.e. the Health Board and Local Authorities), and in particular senior managers. It would be beneficial for further research to examine the perspectives of all staff levels, as well as non-traditional stakeholders, such as third sector organisations, service users and carers. The latter is a gap that has been routinely identified in the literature (e.g. Caine, 2014; Cameron et al., 2014a; Hudson, 2012, Petch et al., 2013), but one that was not consistent with the commission and time restraints of this particular piece of work. The argument for the role of greater inclusivity of voluntary sector organisations in health and social care integration is well articulated (Bull et al 2016).

Overall, despite these limitations, the research was felt to be of sufficient substance to provide a snapshot in time of organisations preparing for the task of "doing things differently, together" - findings which have been (and are being) used to shape conversations about integration in North Wales.

\section{Implications}

Substantive policy change is enabled and supported by clear communication, leadership and vision; and a commitment to an understanding of its aims by those for whom it impacts upon most (i.e. staff and service users). This echoes the finding of Cleaver and Walker (2004) who suggest implementation is most successful when strong leadership at a senior level is combined with a clear plan for implementation that involved practitioners and managers at all levels of the organization. This research suggests the need for clearer, detailed and timelier communication from central government. Such implementation needs to be supported by a flexible approach to training. Welsh Government and local leadership appear to have done an excellent job at selling the principles but a much slower job at confirming the detail of the implied practice change. This research suggests that where such training is late in forthcoming, it creates unnecessary uncertainty and ambivalence towards successful implementation.

This study was of an exploratory rather than evaluative nature, reflecting the timing and size of its commission. A longer study would have enabled some of these pre implementation observations to be compared with post implementation realities. In this context arrangements for Welsh Government evaluation of the Act were only announced on the eve on enactment (Drakeford 2016) and prose three elements of implementation; (i) monitoring policies under the Act during the initial year of implementation, (ii) on-going evaluation, through the national outcomes framework and the local authority performance measurement framework, and (iii) long term one-off evaluation commencing in the third year of the implementation of the Act. The implication here is that longer and more holistic approaches to research support better understanding of policy change from precursors, design, enactment and evaluation. 


\section{Conclusion}

Beyond being exploratory action research to inform implementation in North Wales, this research suggests three broader implications:

1. Government policy and supporting guidance invoking integration, should be more timely, and inclusive in terms of nomenclature, mandation and engagement

2. Local collaboration partnerships should work on developing distinct and truly shared vision, beyond senior management, into frontline staff, communities and citizens

3. Significant policy change is only likely to be one force of organisational and practice change amongst many, and need to be worked with as such evolutionary rather than revolutionary.

The Social Services and Well-being (Wales) Act 2014 ('the Act') symbolises a new direction for Health and Social Care in North Wales - a direction characterised by a focus on the integration and transformation of services and working practices, delivering provision increasingly developed towards communities and citizens. It is not possible to attribute the philosophical and practical changes associated with this to any one event, such as this Act or that budget cut. The impetus has been generated from a broad range of financial, environmental, social, and policy factors. The findings of this study suggest that the shape of Health and Social Care integration in North Wales is unlikely to be fully realised when organisations have implemented the requirements of the Act in 2016, but rather will emerge over time as Health and Social Care continue to respond to, and pre-empt, diverse and complex pressures. In conclusion, delivery of the Act is likely to be embedded in and reflect, rather than shape, the wider economic and socio-political contexts.

\section{Funding}

This research was supported through Welsh Government Transformation Funding.

\section{References}

Alcock, P (2008) Social Policy in Britain 3rd edition London, Palgrave Macmillan.

Bull, D. Bagwell, S. Weston, A and Joy, I. (2016) Untapped Potential: Bringing the voluntary sector's strengths to health and care transformation. London: New Philanthropy Capital

Caine, J., 2014. Integrating people with dementia and their carers into service design. Journal of Integrated Care, 22(3), pp.91-98.

Cameron, A., Lart, R., Bostock, L. and Coomber, C., 2014. Factors that promote and hinder joint and integrated working between health and social care services: a review of research literature. Health \& social care in the community, 22(3), pp.225-233. 
Cleaver, H. and Walker, S., 2004. From policy to practice: the implementation of a new framework for social work assessments of children and families. Child \& Family Social Work, 9(1), pp. 81-90.

Dooris, M. (2013). Expert voices for change: bridging the silos-towards healthy and sustainable settings for the 21st century. Health \& Place, vol. 20, pp. 39-50.

Drakeford, M (2016) Written Statement - Evaluation of the Social Services and Well-being (Wales) Act 2014

http://gov.wales/about/cabinet/cabinetstatements/2016/socialserviceswellbeingact/?la ng=en Last updated 31 March 2016 [Accessed on 07-4-2016]

Fisher, K. and Thomson, C., 2006. Making integration happen: the families first policy experience. Child Abuse Review, 15(6), pp.414-428.

Gleave, R., Wong, I., Porteus, J. and Harding, E., 2010. What is 'More Integration' between Health and Social Care? Results of a Survey of Primary Care Trusts and Directors of Adult Social Care in England. Journal of Integrated Care, 18(5), pp.29-44.

Glendinning, C., 2003. Breaking down barriers: integrating health and care services for older people in England. Health policy, 65(2), pp.139-151.

Heenan, D. and Birrell, D., 2009. Organisational integration in health and social care: some reflections on the Northern Ireland experience. Journal of Integrated Care, 17(5), pp.3-12.

Hudson, B., 2012. Twenty years of health and social care joint working: A journey from Doctor Pangloss to Private Frazer?. Journal of Integrated Care,20(2), pp.115-124.

Humphries, R. (2013). Health and wellbeing boards: policy and prospects. Journal of Integrated Care, vol. 21, no. 1, pp. 6-12

Jones, R., 2011. History and hindrance: the impact of change and churn on integrating health and social care. Research, Policy and Planning, 28(3), pp.199-206.

Kharicha, K., Iliffe, S., Levin, E., Davey, B. and Fleming, C., 2005. Tearing down the Berlin wall: social workers' perspectives on joint working with general practice. Family Practice, 22(4), pp.399-405.

Law Commission (2011). Adult Social Care Law Com No 326, HC 941. London: Stationery Office.

Livingston, W., Davies, N., Huxley, P. and Owen, E. (2015). Integration in North Wales: Localised responses to National agendas. 1st ed. [pdf] Social Services Improvement Agency. Available at: http://www.ssiacymru.org.uk/home.php?page_id=2482 [Accessed 28 Feb. 2016].

Lunts, P., 2012. Change management in integrated care: what helps and hinders middle managers - a case study. Journal of Integrated Care, 20(4), pp.246-256.

Petch, A., 2011. An evidence base for the delivery of adult services. Association of Directors of Social Work, Edinburg. 
Petch, A., Cook, A. and Miller, E., 2013. Partnership working and outcomes: do health and social care partnerships deliver for users and carers?. Health \& social care in the community, 21(6), pp.623-633.

Robertson, H., 2011. Integration of health and social care: A review of literature and models Implications for Scotland. Royal College of Nursing Scotland.

The Social Services and Well-being (Wales) Act 2014, National Assembly for Wales. Available at: http://www.legislation.gov.uk/anaw/2014/4/contents/enacted (Accessed: 28 February 2016).

Shaw, S., Rosen, R. \& and Rumbold, B. (2011). What is Integrated Care? An overview of integrated care in the NHS. London, Nuffield Trust.

Stewart, A. and Maclntyre, G., 2013. Care management in the twenty-first century: Persistent challenges in implementation in the context of the emergence of selfcare. Journal of Integrated Care, 21(2), pp.91-104.

Welsh Assembly Government, (2007). Fulfilled Lives, Supportive Communities. [pdf] Available at:

http://gov.wales/dhss/publications/socialcare/strategies/fulfilledlives/fulfilledlivese.pdf?lan g=en (Accessed: 28 February 2016).

Welsh Assembly Government, (2011). Sustainable Social Services for Wales. [pdf] Available at: http://gov.wales/docs/dhss/publications/110216frameworken.pdf (Accessed: 28 February 2016).

Welsh Government (2016) Wales set for new fairer, stronger, sustainable social services system http://gov.wales/newsroom/healthandsocialcare/2016/160405socialservices/?skip=1\&lang=en Issued Tuesday 05 April 2016 [Accessed 07-04-2016] 